\title{
Roadmap Consensus on Carotid Artery Plaque Imaging and Impact on Therapy Strategies and Guidelines: An International, Multispecialty, Expert Review and Position Statement
}

\author{
(D) L. Saba, (D). Brinjikji, (D).D. Spence, (D) M. Wintermark, (D). Castillo, (D) G.J. de Borst, (D) Q. Yang, (D). Yuan, (D)A. Buckler, \\ (D) M. Edjlali, (D)T. Saam, (DD. Saloner, DB.K. Lal, DD. Capodanno, (D). Sun, (D) N. Balu, (D) R. Naylor, (D) A.v.d. Lugt, \\ (D)B.A. Wasserman, (D) M.E. Kooi, (D). Wardlaw, (D). Gillard, (D) G. Lanzino, (D). Hedin, (DD. Mikulis, (D)A. Gupta, (D).K. DeMarco, \\ (D) C. Hess, (D).V. Goethem, (D)T. Hatsukami, (D). Rothwell, (D)M.M. Brown, and (D) A.R. Moody
} it $\mathrm{O} \equiv$

\begin{abstract}
SUMMARY: Current guidelines for primary and secondary prevention of stroke in patients with carotid atherosclerosis are based on the quantification of the degree of stenosis and symptom status. Recent publications have demonstrated that plaque morphology and composition, independent of the degree of stenosis, are important in the risk stratification of carotid atherosclerotic disease. This finding raises the question as to whether current guidelines are adequate or if they should be updated with new evidence, including imaging for plaque phenotyping, risk stratification, and clinical decision-making in addition to the degree of stenosis. To further this discussion, this roadmap consensus article defines the limits of luminal imaging and highlights the current evidence supporting the role of plaque imaging. Furthermore, we identify gaps in current knowledge and suggest steps to generate high-quality evidence, to add relevant information to guidelines currently based on the quantification of stenosis.
\end{abstract}

ABBREVIATIONS: $\mathrm{AHA}=$ American Heart Association; IPH = intraplaque hemorrhage; LRNC = lipid-rich necrotic core

$\Delta$ cute ischemic stroke is a major cause of morbidity and mortality worldwide, accounting for approximately $5 \%$ of disability-adjusted life years and $>10 \%$ of deaths. Approximately $20 \%$ of patients with stroke/TIA have an ipsilateral carotid stenosis of
$>50 \%,{ }^{1,2}$ and about one-third (about $10 \%$ all patients with stroke) had no warning symptoms such as transient ischemic attacks. ${ }^{3}$

Carotid artery stenosis is a well-established risk factor for ischemic stroke. Determining the best primary and secondary
Received November 18, 2020; accepted after revision January 26, 2021.

From the Department of Radiology (L.S.), University of Cagliari, Cagliari, Italy; Departments of Radiology (W.B.) and Neurosurgery (G.L.) Mayo Clinic, Rochester, Minnesota; Stroke Prevention and Atherosclerosis Research Centre (J.D.S.), Robarts Research Institute, Western University, London, Ontario, Canada; Department of Neuroradiology (M.W.), Stanford University and Healthcare System, Stanford, California; Department of Radiology (M.C.), University of North Carolina, Chapel Hill, North Carolina; Department of Vascular Surgery (G.J.d.B.), University Medical Center Utrecht, Utrecht, the Netherlands; Department of Radiology (Q.Y.), Xuanwu Hospital, Capital Medical University, Beijing, China; Departments of Radiology (C.Y., J.S., N.B.) and Surgery (T.H.), University of Washington, Seattle, Washington; Elucid Bioimaging (A.B.), Boston, Massachusetts; Department of Molecular Medicine and Surgery (U.H.), Karolinska Institutet, Stockholm, Sweden; Department of Neuroradiology (M.E.), Université Paris-Descartes-Sorbonne-ParisCité, IMABRAIN-INSERM-UMRI266, DHU-Neurovasc, Centre Hospitalier SainteAnne, Paris, France; Department of Radiology (T.S.), University Hospital, Ludwig Maximilian University of Munich, Munich, Germany; Radiologisches Zentrum (T.S.), Rosenheim, Germany; Departments of Radiology and Biomedical Imaging (D.S.,C.H.), University of California San Francisco, San Francisco, California; Department of Vascular Surgery (B.K.L.), University of Maryland School of Medicine, Baltimore, Maryland; Division of Cardiology (D.C.), A.O.U. Policlinico "G. Rodolico-San Marco," University of Catania, Italy; The Leicester Vascular Institute (R.N.), Glenfield Hospital, Leicester, UK; Department of Radiology and Nuclear Medicine (A.v.d.L.), Erasmus MC, University Medical Center Rotterdam, Rotterdam, the Netherlands; The Russell H. Morgan Department of Radiology and Radiological Science (B.A.W.), Johns Hopkins Hospital, Baltimore, Maryland; Department of Radiology and Nuclear Medicine (M.E.K.), CARIM School for Cardiovascular Diseases, Maastricht University Medical Center, Maastricht, the Netherlands; Centre for Clinical Brain Sciences (J.W.), United Kingdom Dementia
Research Institute and Edinburgh Imaging, University of Edinburgh, Edinburgh, UK; Christ's College (J.G.), Cambridge, UK; Department of Vascular Surgery (U.H.), Karolinska University Hospital and Karolinska Institute, Stockholm, Sweden; Joint Department of Medical Imaging and the Functional Neuroimaging Laboratory (D.M.), University Health Network, Toronto, Ontario, Canada; Department of Radiology (A.G.), Weill Cornell Medical College, New York, New York; Walter Reed National Military Medical Center and Uniformed Services University of the Health Sciences (J.K.D.), Bethesda, Maryland; Faculty of Biomedical Sciences (J.V.G.), University of Antwerp, Antwerp, Belgium; Centre for Prevention of Stroke and Dementia (P.R.), Nuffield Department of Clinical Neurosciences, John Radcliffe Hospital, University of Oxford, UK; Stroke Research Centre (M.M.B.), Department of Brain Repair and Rehabilitation, University College of London Queen Square Institute of Neurology, University College London, UK; and Department of Medical Imaging (A.R.M.), University of Toronto, Toronto, Ontario, Canada.

The views expressed in this article are those of the authors and do not reflect the official policy of the Department of Army/Navy/Air Force, Department of Defense, or US Government. The identification of specific products or scientific instrumentation does not constitute endorsement or implied endorsement on the part of the author, Department of Defense, or any component agency.

Please address correspondence to Luca Saba, MD, University of Cagliari, Azienda Ospedaliero Universitaria di Cagliari, polo di Monserrato, Provincia di Cagliari, Italy; e-mail: lucasaba@tiscali.it; @lucasabalTA

\footnotetext{
- Indicates open access to non-subscribers at www.ajnr.org

Indicates article with online supplemental data.

http://dx.doi.org/10.3174/ajnr.A7223
} 


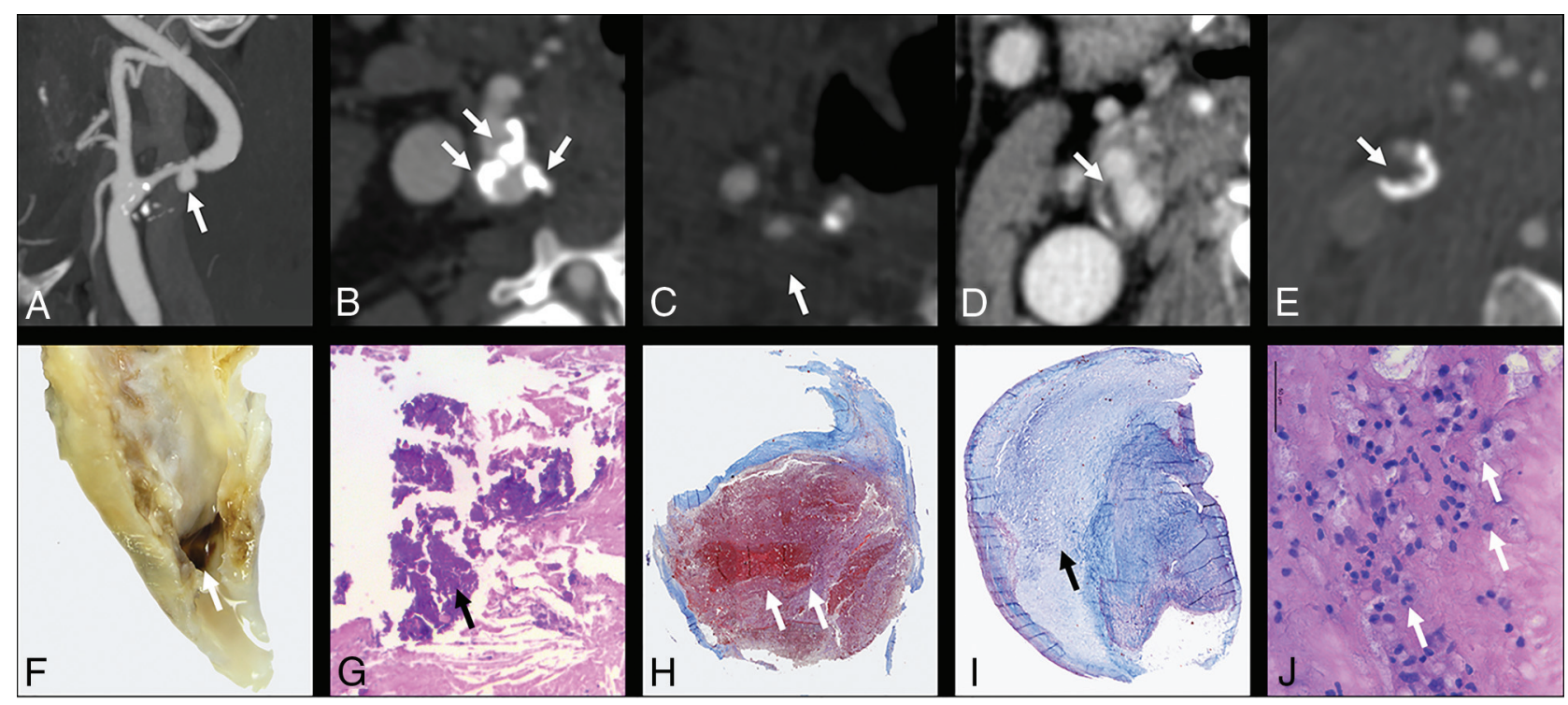

FIG 1. Different CT features. A, Plaque ulceration (arrow) is shown with the corresponding macroscopic specimen (F). B, Multiple coarse calcifications (white arrows) within the plaque are visible with the corresponding example in the H\&M histologic view (G, arrow points at a calcification). The IPH is visible in $H$ (white arrows) with the corresponding CTA that shows hypodense plaque in $C$ (Hounsfield unit value= 18; white arrow). I, A stable plaque with a prominent fibrous cap with the major part of the plaque with collagenous connective tissue (black arrow) is shown with the corresponding CT section ( $D$, white arrow). $E$, The presence of a hypodense plaque (Hounsfield unit $=37$ ) with the corresponding histopathologic slide showing multiple inflammatory cells ().

stroke prevention strategies for asymptomatic and symptomatic patients with carotid stenosis is a priority. The current guidelines for the management of both symptomatic and asymptomatic atherosclerosis are based on randomized trials comparing medical therapy with surgical interventions using the degree of stenosis together with symptom status without consideration of plaque morphology and composition. These were published before the advent of vessel wall imaging using MR imaging and high-resolution CT angiography (Figs 1 and 2)

From the first NASCET report that demonstrated the association between high-grade stenosis and outcome, a important evolution in both the surgical approach and medical treatment has occurred. The risk of morbidity and mortality during revascularization procedures, in particular during carotid endarterectomy, has decreased, with a reduction of mortality and severe complications. ${ }^{4-6}$ Moreover, several trials have provided evidence strengthening conservative medical treatment of carotid disease, including the protective effects of high-dose statin therapy and anti-inflammatory therapy such as the interleukin- $1 \beta$ innate immunity pathway. ${ }^{7-10}$ Recent meta-analyses provide evidence that atherosclerosis can be reversed ("plaque regression") with highdose lipid-lowering therapy, ${ }^{11}$ and high-dose statins may shift vulnerable plaque from a high lipid content to a more stable calcified plaque. ${ }^{11-13}$ Imaging of carotid plaque morphology may, therefore, more accurately reflect the pathobiology of the plaque itself, allowing estimation of plaque risk. ${ }^{14}$ This could lead to a more cost-effective selection of expensive endovascular/surgical management options. 9,15

It has been $>30$ years since the landmark carotid surgery trials defined the degree of carotid stenosis as an important imaging biomarker for surgical management, leading to improved outcomes. However, despite this advance, carotid atherosclerotic disease still accounts for significant morbidity and mortality suggesting the need for a variation in the management and risk stratification of subjects with carotid artery pathology based on the new diagnostic potentialities.

The purpose of this consensus document is to review the current literature, identify new imaging metrics that are associated with future cerebrovascular events and to discuss therapeutic options for specifically targeting these features. Having done so, a roadmap for multicenter diagnostic and therapeutic trials incorporating these imaging biomarkers as inclusion criteria is provided to assess patient outcome compared with management based only on the degree of stenosis.

\section{Summary and Analysis of Existing Guidelines}

In this section, we have developed a summary and analysis of existing guidelines. Currently, moderate (50\%-69\%) and severe $(70 \%-99 \%)$ carotid artery stenoses are considered the key parameters together with the symptomatic/asymptomatic status of the patient in deciding management approaches. These are based primarily on NASCET results. ${ }^{16,17}$ A report published in Stroke, in $2015,{ }^{18}$ identified 34 guidelines from 23 different regions/countries in 6 languages, in which 4 scenarios were highlighted:

1. Asymptomatic patient at average surgical risk with stenosis

2. Asymptomatic patient at high surgical risk (because of comorbidities, vascular anatomy, or undefined reasons) with stenosis

3. Symptomatic patient at average surgical risk with stenosis

4. Symptomatic patient at high surgical risk (because of comorbidities, vascular anatomy, or undefined reasons) with stenosis

In all 4 scenarios, the degree of stenosis ( $\geq 50 \%$ ) was the key point considered for treatment. In 33/34 guidelines, treatment 


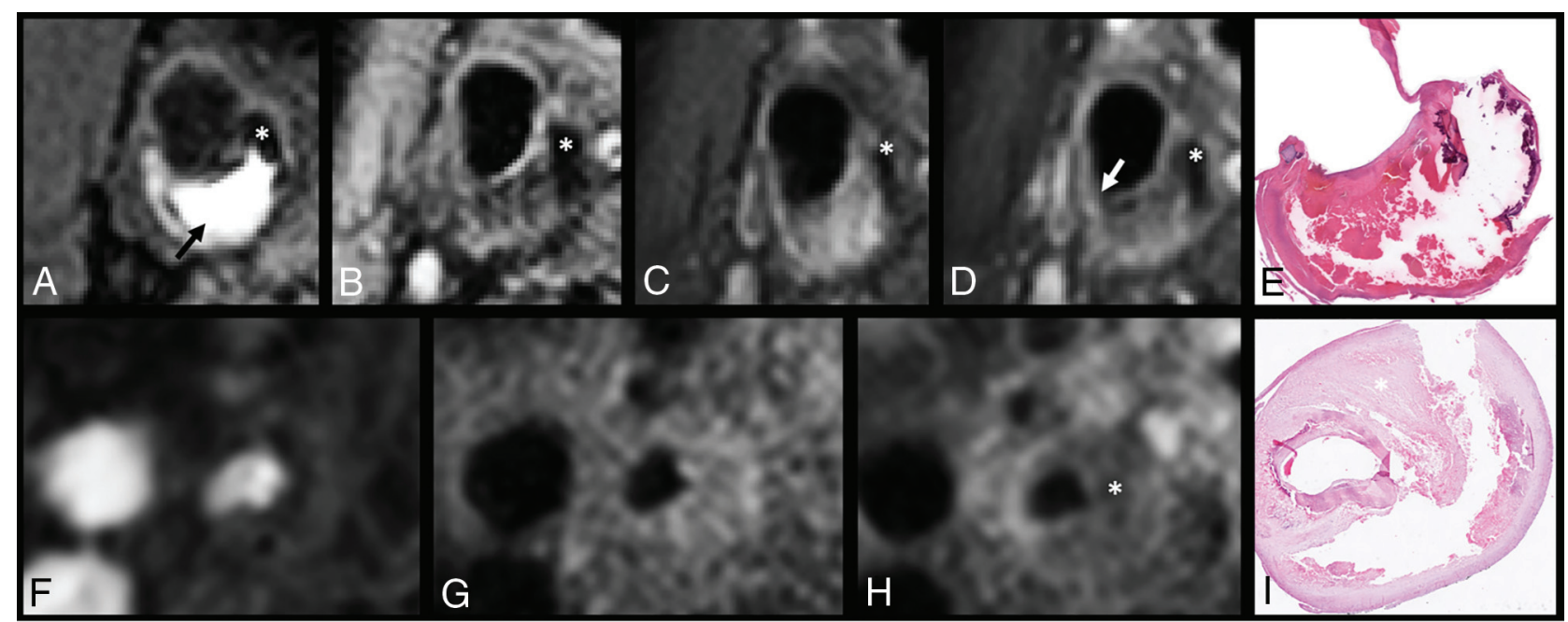

FIG 2. Upper row: Coregistered MPRAGE (A), T2-weighted TSE (B), pre- and postcontrast TIWI TSE MR images (C and D), and a corresponding histologic section $(E)$ of a cross-section of the carotid artery with plaque. A large intraplaque hemorrhage can be recognized as a hyperintense region compared with surrounding muscle tissue in the bulk of the plaque on the MPRAGE image (arrow). Calcification can be identified as a region with hypointense signal on all $4 \mathrm{MR}$ imaging weightings. On the postcontrast T1-weighted TSE image, the region with signal enhancement shows the fibrous cap (between the lumen and intraplaque hemorrhage). The disruption of this enhancement (white arrow) indicates that the fibrous cap is thin or ruptured at this location. Lower row: Coregistered TOF (F), pre- and postcontrast Tl-weighted TSE MR images (G and H), and the corresponding histologic section (I) of a cross-section of the carotid artery with a plaque. An LRNC is present in the bulk of the plaque with no or slight contrast enhancement on the postcontrast TIWI (asterisk).

was considered only for symptomatic subjects. For symptomatic patients with high carotid endarterectomy risk, medical treatment alone was not endorsed in any guidelines, though the possibility was considered as an alternative option in $2 .{ }^{19-21}$ Only 1 guideline advised medical treatment alone for patients with asymptomatic carotid stenosis.

The European Society for Vascular Surgery and the European Society of Cardiology developed consensus recommendations for asymptomatic patients, recommending that plaque morphology features be considered. ${ }^{22,23}$ The only variation compared with the 2011 guidelines was that carotid endarterectomy is indicated in the presence of $\geq 1$ imaging characteristic that may be associated with high stroke risk in asymptomatic subjects. These data indicate that the guidelines currently used worldwide do not consider the imaging-based plaque morphology/composition as a parameter for the therapeutic option and that the class of risk is based on the mere degree of stenosis and symptomatic/asymptomatic status of the patient.

However, in past years, landmark articles showing the impact of imaging-based features of carotid artery plaque vulnerability in symptomatic and asymptomatic patients with mild stenosis ${ }^{24}$ and the benefit of conservative medical treatment for the plaque stabilization and reversion have been published, ${ }^{7,9,13}$ highlighting the need for changes in the forthcoming guidelines.

\section{Evidence That Imaging of Plaque Composition Predicts Ischemic Stroke Risk}

In the past years, evidence has accumulated in pathology and imaging fields demonstrating that plaque composition plays a key role in the vulnerability of the carotid artery plaque.

Histopathology of Unstable Plaque. Coronary atherothrombosis was described $>150$ years ago, and carotid stenosis was coupled with the pathophysiology of ischemic stroke $>70$ years ago. The associations between histopathologic features and increased risk of stroke were described in the 1970s and 1980s, noting the association between fibrous cap rupture and thromboembolism (Fig $1)^{25-27}$ and identification of intraplaque hemorrhage (IPH) as a marker of recent symptom-producing plaques. ${ }^{28-30}$

Histopathologic studies showed that vulnerable plaques were characterized by a thin or ruptured fibrous cap, endothelial erosions, enhanced inflammation, large lipid-rich necrotic cores, immature intraplaque neovascularity, and IPH, whereas stable and asymptomatic lesions typically contain more fibrous tissue and more calcification. ${ }^{31,32}$

However, the authors found that ulceration, IPH, and organizing or organized thrombi were also found in both symptomatic and asymptomatic stenotic plaques examined pathologically, ${ }^{29,33-40}$ suggesting a complex pathobiologic scenario for the plaque rupture. The authors found that biologic variability in plaque morphology also plays a role.

Fisher and Ojemann ${ }^{41}$ noted that "the variations in the microscopic appearance of the plaque contents seemed to be unending." The authors found that the position of the lipid/necrotic core and thinning of the cap may be the most significant features predisposing to plaque rupture. ${ }^{27,40}$ Most interesting, decreasing fibrous cap thickness increases the circumferential stress on a plaque, whereas increasing stenosis severity decreases circumferential stress. ${ }^{42}$ This finding may help to explain why stroke risk tends to be lower in patients with critical stenosis compared with high-grade stenosis.

The American Heart Association (AHA), in 1995, published ${ }^{43}$ a detailed classification scheme designed to be used as a histologic template for images obtained by a variety of invasive and noninvasive techniques in the clinical setting. In the AHA scheme 


\begin{tabular}{|c|c|}
\hline AHA Classification & Carotid MR Imaging-Based AHA Classification from Cai et a ${ }^{45}$ \\
\hline Type I: initial lesion with foam cells & Type I-II: near-normal wall thickness, no calcification \\
\hline Type II: fatty streak with multiple foam cell layers & \\
\hline Type III: pre-atheroma with extracellular lipid pools & $\begin{array}{l}\text { Type III: diffuse intimal thickening or small eccentric plaque with } \\
\text { no calcification }\end{array}$ \\
\hline Type IV: atheroma with a confluent extracellular lipid core & $\begin{array}{l}\text { Type IV-V: plaque with a lipid or necrotic core surrounded by } \\
\text { fibrous tissue with possible calcification }\end{array}$ \\
\hline Type V: fibroatheroma & \\
\hline $\begin{array}{l}\text { Type VI: complex plaque with possible surface defect, hemorrhage, } \\
\text { or thrombus }\end{array}$ & $\begin{array}{l}\text { Type VI: complex plaque with possible surface defect, hemorrhage, } \\
\text { or thrombus }\end{array}$ \\
\hline Type VII: calcified plaque & Type VII: calcified plaque \\
\hline Type VIII: fibrotic plaque without lipid core & $\begin{array}{l}\text { Type VIII: fibrotic plaque without lipid core and with possible small } \\
\text { calcifications }\end{array}$ \\
\hline
\end{tabular}

(Table), revised in 2000, ${ }^{44}$ the lesions are designated by Roman numerals, which indicate the usual sequence of lesion progression from the initial lesion, type I to type VIII, in which the fibrous tissue changes within the plaque predominate. This classification was in MR imaging and CT studies (Table). ${ }^{45,46}$ Virmani et $\mathrm{al}^{47}$ built on the Stary system to more closely focus on erosion, rupture, and thinning of the fibrous cap, increasingly prevalent in the population due to widespread use of statins. The result of these developments in plaque phenotyping have converged into the most widely accepted system in use today, ${ }^{48}$ which also suggests that further development will be possible once modalities to recognize the lesion by noninvasive means are addressed in this roadmap.

Plaque Vulnerability in Patients with Mild or No Stenosis. Conventional angiography tends to underestimate the extent of disease because the lumen can be maintained through positive remodeling of the vessel wall, further exaggerated by the anatomy of the carotid bulb. Patients with lesser degrees of stenosis represent a significant proportion of patients with stroke. In the NASCET trial, $>40 \%$ of those with stroke on follow-up were from the $<50 \%$ stenosis group. ${ }^{16}$ Mild stenoses, albeit associated with reduced risk of producing ischemic events, are much more common than severe stenoses and, thus, are associated with a substantial number of events: The estimated prevalence of carotid stenosis of $\geq 50 \%$ in the general population ranges from $2 \%$ to $8 \%$ and the estimated prevalence of stenosis of $\geq 80 \%$ ranges from $1 \%$ to $2 \%{ }^{49}$ Detection of high-risk lesions in ever decreasing degrees of carotid stenosis will potentially require either higher resolution imaging or more conspicuous imaging biomarkers.

Features of plaque vulnerability are related to the occurrence of ischemic events independent of the degree of stenosis: Studying plaques with lower levels of luminal stenosis separates the effects of hemodynamic compromise caused by the luminal narrowing and vessel wall pathology on clinical outcomes. In a group of patients studied recently presenting with imagingproved acute stroke with no significant stenosis $(<50 \%)$, up to half were shown to have IPH in the carotid artery ipsilateral to the stroke, suggesting a possible source of cerebral $^{50,51}$ emboli. Some morphologic features, such as ulceration, are also associated with the occurrence of ischemic events independent of the degree of stenosis. ${ }^{52}$ In a meta-analysis of 8 studies including 689 patients, the presence of IPH at baseline was associated with a 6fold higher risk of cerebrovascular events, with an annualized event rate of $17.7 \%$ compared with $2.43 \%$ in patients with no IPH. ${ }^{53}$ In a separate meta-analysis of 9 studies and 779 subjects, the hazard ratios for subsequent stroke/TIA were 4.59 for IPH, 3.00 for lipid-rich necrotic core (LRNC), and 5.93 for thin/ruptured fibrous cap. ${ }^{54}$ Last, another meta-analysis recently published in 2019, including 560 patients with symptomatic and 136 patients with asymptomatic carotid stenosis, reported that the presence of IPH at baseline increased the risk of ipsilateral stroke both in symptomatic (hazard ratio $=10.2 ; 95 \%$ CI, 4.6-22.5) and asymptomatic (hazard ratio $=7.9 ; 95 \%$ CI, 1.3-47.6) patients. Among patients with symptomatic carotid stenosis, annualized event rates of ipsilateral stroke in those with IPH versus those without IPH were $9.0 \%$ versus $0.7 \%$ ( $<50 \%$ stenosis), $18.1 \%$ versus $2.1 \%$ (50\%-69\% stenosis), and $29.3 \%$ versus $1.5 \%$ (70\%-99\% stenosis). Multivariate analysis identified IPH (hazard ratio = 11.0; 95\% CI, 4.8-25.1) and a severe degree of stenosis (hazard ratio $=3.3 ; 95 \% \mathrm{CI}, 1.4-7.8)$ as independent predictors of ipsilateral stroke. $^{55}$

Plaque with Severe Stenosis and a Low Likelihood of Rupture. Several studies have demonstrated that plaque calcification is a stabilizing factor in carotid artery stenosis and is more common in asymptomatic than in symptomatic plaques. ${ }^{56}$ Histopathologic studies demonstrated that plaques with a high burden of calcification have lower rates of inflammation, macrophage burden, neovascularization, and IPH, lending further support to the use of plaque imaging as a risk-stratification tool. ${ }^{14}$

\section{Plaque Progression and Regression}

With improvements in MR imaging, sonography, and CT, it is now possible to directly visualize the carotid wall volume and plaque composition as the vessel wall disease evolves from early/ mild atherosclerosis to late-stage/severe-stage atherosclerosis. ${ }^{57}$ Progression of plaque morphology with increasing vessel wall volume or progression of plaque components with increasing size of vulnerable plaque features or both are associated with an increased risk of future cerebrovascular and cardiovascular events. ${ }^{58}$ Furthermore, direct visualization of the plaque response to medical therapy offers the potential for individualization of atherosclerosis treatment. ${ }^{59}$ To use imaging for assessing the 
response of carotid plaque to drug therapy, one needs to determine the reproducibility of the imaging.

Evidence of Plaque Progression and Regression. In a prospective, case-controlled study of asymptomatic patients with moderate carotid stenosis, LRNC size increased in plaques with IPH compared with plaques with no IPH. ${ }^{60}$ The role of IPH-induced plaque progression was demonstrated in a later study of mildly stenotic asymptomatic patients in whom IPH was found to significantly increase plaque size. ${ }^{61}$ This finding suggests that IPH may occur before stenosis becomes severe and may drive the stenotic phenotype. ${ }^{59}$ In a prospective study of asymptomatic patients with moderate stenosis, the LRNC size governed the risk of future surface disruption, suggesting that urgent lipid-lowering therapy to prevent the transition from stable to unstable atherosclerotic disease may be warranted. ${ }^{62}$

Plaque progression is a major risk factor for the development of future ischemic events. Longitudinal studies have demonstrated that the presence of plaque hemorrhage ${ }^{63}$ (as determined by MR imaging) or a hypoechoic plaque (on sonography) is a major risk factor for plaque progression. ${ }^{64}$ Another mechanism for rapid significant progression of plaque volume is silent plaque rupture and healing. ${ }^{65}$

With regard to evidence of plaque regression, lipid-lowering treatment, predominately with statin therapy, has been shown to decrease carotid plaque size and composition. Corti et $\mathrm{al}^{66}$ were the first to show a decrease in vessel wall thickness and vessel wall area. Observational studies have all used the 1-year timeframe to study changes in vessel wall size. ${ }^{59}$ Because wall volume showed a greater reduction in more diseased segments with statin therapy, ${ }^{67}$ it seems that carotid MR imaging is best suited to yearly follow-up of patients with known carotid stenosis. Studies have shown that statin therapy is associated with a decrease in LRNC and an increase in fibrous tissue, ${ }^{68}$ which precedes any reduction in plaque volume. ${ }^{67}$ Information from natural history studies suggests that IPH may override the beneficial effects of statin therapy, but the statin type and dose were not randomized or uniform. ${ }^{61}$ No prospective trials exist testing the hypothesis that the deleterious effects of IPH can be modified with very intensive lipid-lowering therapy.

Underhill and Yuan ${ }^{59}$ summarized the use of MR imaging monitoring of carotid plaque in clinical trials, noting the following: 1) The rate of change is slower in plaques with $<50 \%$ LRNC volume, though improved image quality may allow detection of change at 6 months, 2) changes in plaque composition precede changes in plaque morphology, and 3) LRNC at baseline is needed to monitor treatment effect with MR imaging.

Sonography provides a sensitive measure of carotid plaque regression. Carotid plaques are focal and progress along the artery wall 2.4 times faster than they thicken. ${ }^{69}$ Spence and Hackam $^{70}$ reported their experience in 4387 patients imaged with serial carotid total plaque area. In this cohort, they intensified medical therapy for patients with documented plaque progression despite guideline-based medical therapy. By "treating arteries instead of risk factors," they significantly decreased the incidence of plaque progression and cardiovascular events, and microemboli on transcranial Doppler sonography markedly declined with intensification of medical therapy. ${ }^{71}$

\section{Updated Drug Therapy: Evidence and Impact}

It is demonstrated that a group of potentially modifiable risk factors (hypertension, regular physical activity, dyslipidemia, diet, obesity, psychosocial factors, smoking, cardiac causes, alcohol consumption, and diabetes mellitus) account for $90 \%$ of the population-attributable risks of stroke, ${ }^{72}$ and some classes of drugs can significantly impact these factors. In this section we will explore the latest evidence in the use of imaging and its impact on the drug therapy in the prevention of stroke.

Lipid-Lowering Therapy. Studies have shown that treatment with statins reduces the risk of stroke in patients at high risk for atherosclerosis by $21 \%$ and that this risk reduction has been associated with each 1-mmol/L (39 mg/dL) decrease in low-density lipoprotein. ${ }^{73,74}$ In a meta-analysis by Cannon et al, ${ }^{75}$ published in 2006, high-intensity statin treatment reduced nonfatal cardiovascular events and led to lower stroke incidence, even in healthy individuals, with low-density lipoprotein levels of $<130 \mathrm{mg} / \mathrm{dL}$ and high-sensitivity C-reactive protein levels of $>2 \mathrm{mg} / \mathrm{L}^{76}$ Two randomized controlled trials have shown improved cardiovascular diseases outcomes with the addition of nonstatin lipidlowering medications: ezetimibe ${ }^{77}$ and evocolumab. ${ }^{78}$ The proprotein convertase subtilisin/kexin type 9 inhibitors achieve very low nonstatin low-density lipoprotein thresholds. ${ }^{79}$ A study published in 2016 showed that the duration of statin therapy is associated with the regression of carotid plaque neovasculature measured with dynamic contrast-enhanced MR imaging, ${ }^{80}$ and these results were confirmed by another group in $2019,{ }^{81}$ again with dynamic contrast-enhanced MR imaging, which demonstrated that statins rapidly and significantly decreased adventitial and plaque neovascularization at 3 months.

Antiplatelet Therapy. In a study published in $1997,{ }^{82}$ the introduction of aspirin within 48 hours after ischemic stroke led to a significant reduction in recurrence within 2 weeks, ${ }^{83}$ and the addition of dipyridamole and clopidogrel added significant benefit to secondary stroke prevention. ${ }^{84-87}$ Evidence suggests that while benefit occurs within 48 hours of starting aspirin for stroke prevention, there is no further benefit after 2 months. ${ }^{88}$ The benefits of long-term treatment with dual antiplatelet therapy (aspirin plus clopidogrel) in patients with acute coronary syndrome were never replicated in patients with stroke and are associated with more bleeding complications. ${ }^{53,62,89}$ The impact of antiplatelet therapy on carotid artery plaque has been explored: in 2019, a sonography-based trial was published that explored the efficacy and usefulness of an antiplatelet drug (cilostazol) on the progression of carotid intima-media thickness, and the authors found that it may inhibit plaque formation. ${ }^{90}$

Anticoagulation Therapy. In 2017, Eikelboom et $\mathrm{al}^{91}$ published the results of the Cardiovascular Outcomes for People Using Anticoagulation Strategies (COMPASS) trial. In this study, patients with coronary, peripheral, and carotid artery disease (symptomatic or asymptomatic) were included, and a combination of an anticoagulant ( $2.5 \mathrm{mg}$ of rivaroxaban twice a day) and aspirin proved superior to aspirin alone and $5 \mathrm{mg}$ of rivaroxaban twice a day. The outcome of ischemic and hemorrhagic events 


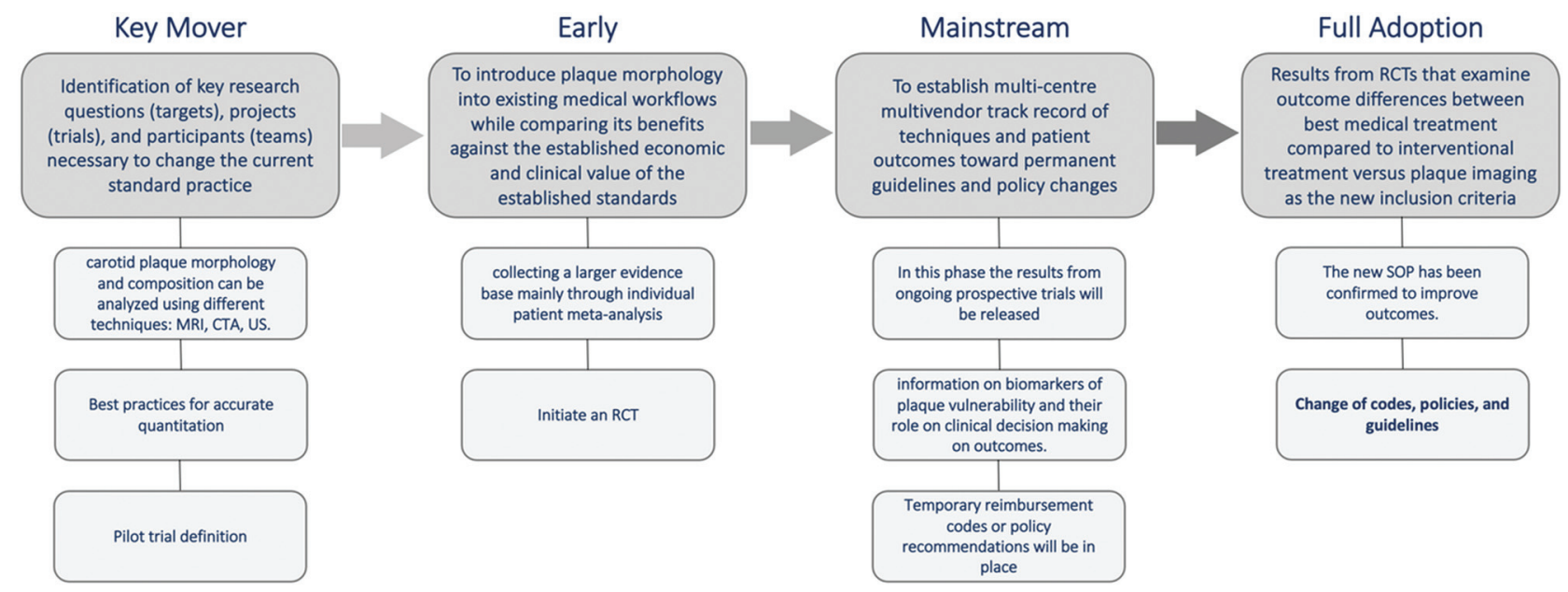

FIG 3. Roadmap graphic flow chart showing the 4 phases: key mover, early, mainstream, and full adoption. The lighter gray boxes represent the components of the various stages of the roadmap. RCT indicates randomized controlled trial; SOP, standard of practice; US, ultrasound.

was significantly in favor of patients in the combined treatment group, and efficacy outcomes were mainly driven by a $50 \%$ relative-risk reduction in ischemic stroke risk $(P<.001)$. The recently published Rivaroxaban Versus Aspirin in Secondary Prevention of Stroke and Prevention of Systemic Embolism in Patients with Recent Embolic Stroke of Undetermined Source (NAVIGATE ESUS) trial, performed in 4723 participants with available intracranial CTA or MRA, showed that among participants with evidence of systemic atherosclerosis by either history or imaging $(n=3820)$, recurrent ischemic stroke rates were similar among those assigned to rivaroxaban (5.5\%/year) versus aspi$\operatorname{rin}(4.9 \%$ /year $)($ hazard ratio $=1.1 ; 95 \% \mathrm{CI}, 0.84-1.5) .{ }^{92}$

Anti-Inflammatory Therapy. Atherosclerosis is considered a predominantly a lipid-driven, chronic, low-grade inflammatory disease of the arterial wall. ${ }^{93}$ Anti-inflammatory strategies are increasingly being considered as an attractive strategy to further reduce the residual risk of atherosclerotic cardiovascular disease. ${ }^{94}$ The administration of canakinumab (a monoclonal antibody against interleukin-1 $\beta$ ) reduces the incidence of nonfatal myocardial infarction, nonfatal stroke, and cardiovascular death. Colchicine is another anti-inflammatory drug that may result in plaque stabilization, ${ }^{95}$ reducing the incidence of noncardioembolic ischemic stroke in patients with stable coronary artery disease. ${ }^{96}$ Promising imaging-based studies have shown the impact of anti-inflammatory therapy on plaque progression and composition in the coronary arteries, ${ }^{97}$ suggesting similar effects and ability to assess them in the carotid arteries as addressed by this roadmap.

\section{Suggested Roadmap}

There are 2 related-but-distinct clinical tasks, phenotype classification to categorize patients to their individual disease mechanism to identify the treatments to which they would most likely respond, and risk stratification to identify how urgent interventional treatments may be, to allow patients to benefit from tailored therapeutics to ultimately lower or reverse disease progress and ultimately shift the at-risk population to less acute manifestations of disease.

Sufficient data already exist to formally incorporate some plaque imaging in the management of atherosclerotic carotid artery disease. It is becoming increasingly important to begin the development of a common roadmap for changing the current standard of practice. We propose a 4-phase roadmap (Fig 3). This section outlines the broad overview of the roadmap, and more details are given in the Online Supplemental Data.

Key Mover (The Phase in Which the Field Has Been). Identification of key research questions (targets), projects (trials), and participants (teams) necessary to change the current standard of practice is currently confined to considering the degree of stenosis and the symptom status of the patients. This change begins by examination of existing evidence that is valuable for identifying existing knowledge gaps through systematic reviews. The results of these reviews can then be used to formulate key research priorities for guiding the development of randomized controlled trials. Outcomes from such randomized controlled trials can then be used to initiate policy discussions, including clinical implementation recommendations and the development of new reimbursement codes as required.

Early (The Phase the Field Is Entering). In this early phase, one introduces plaque morphology into existing medical workflows while comparing its benefits against the established economic and clinical values of the established standards. One must start the development of local reimbursement codes/policies in readiness for a larger body of evidence of efficacy and patient benefit. Among the most important activities of this phase is to transition beyond retrospective studies to prospective ones. The retrospective studies are inherently limited due to the fundamental confounding of the current standard of care with the incidence of events; the ability to study positive benefits of plaque morphology assessment as to the improvement in patient outcomes can only be properly studied in 2-arm studies that allow study of the hypothesized improvement without being hampered by data collection that, by definition, is not allowed to use it. The data from 
these studies are expected to develop a better tool for determining the best treatment option for atherosclerosis and inform a better standard of care to reduce the incidence of adverse neurologic symptomatology and poor outcome (eg, ischemic stroke) for patients with known or suspected carotid artery disease.

Mainstream. To reach the mainstream stage, one must address the economic impact, and indications of different organizations should be taken into account to identify an optimal balance in terms of diagnostic stratification of the risk and economic impact of the process. One must establish a multicenter, multivendor track record of techniques and patient outcomes toward permanent guidelines and policy changes. A collaborative and central data base construction for rapid, large data collection and analysis would accelerate this process. Standardized imaging protocols would allow accrual from both clinical (eligible retrospective and prospective) and ongoing research imaging, with capture of standardized patient clinical data ideally with follow-up, requiring appropriate patient consent. ${ }^{98}$

Full Adoption. Results from randomized controlled trials that examine outcome differences between the best medical treatment compared with interventional treatment (carotid endarterectomy) with treatment selection randomized to the current standards (degree of stenosis) versus plaque imaging as the new inclusion criteria will be adopted. Change in clinical practice would lead to an update of policies, guidelines, and billing codes. In parallel with the stages as they effect treatment of patients with signs and symptoms, there is an even broader application in population-based screening. Whereas the US Preventive Services Task Force has presently recommended against screening, ${ }^{99}$ the nature of these assessments is to await the development of more powerful technologies and/or the evolution of disease prevalence until such capability is considered to have reached a crossover point. No doubt the stages that we have identified will provide additional input to this process. Regardless of whether population-based screening does or does not reach the point of being recommended, our roadmap will meet the needs of the patients with signs and symptoms regardless and, in so doing, increasingly provide screening options for patient subpopulations that would also benefit.

\section{CONCLUSIONS}

In this roadmap consensus article, we have defined the limits of luminal imaging and highlight current evidence supporting the role of plaque imaging in risk stratification and treatment of carotid artery atherosclerosis and stroke. These recommendations are supported by evidence that highlights the limits of risk stratification based on the degree of luminal stenosis alone and emphasize the predictive power of other features such as the presence of IPH. Outcome trials, which confirm image-based information and can act as a primary parameter for choosing therapeutic interventions and predicting outcomes, are fundamental for the full adoption of a plaque-imaging-based approach. This body of evidence needs to be merged with evidence from trials that show the effects of pharmaceutical agents to better understand the overall benefits of incorporating plaque imaging metrics. This roadmap details the process for acquiring the necessary high-quality evidence to support the incorporation of plaque imaging in risk stratification and the management of carotid artery atherosclerotic disease.

\section{ACKNOWLEDGMENTS}

The authors would like to express their deepest gratitude to Riccardo Cau, Alessandra Serra, Mueez Aizaz, and Mohamed Kassem for their support and assistance with this project

Disclosures: Mauricio Castillo_UNRELATED: Employment: University of North Carolina. Peter Rothwell—UNRELATED: Board Membership: ARRIVE Trial Executive Committee; Consultancy: BMS Axiomatic Trial Data and Safety Monitoring Board; Payment for Lectures Including Service on Speakers Bureaus: Abbott for lecture on Patent Forame Ovale closure; Other: lecture on TIA for AstraZeneca. Max Wintermark—UNRELATED: Consultancy: Magnetic Insight, Subtle Medical, EMTensor, Icometrix, Nous Infosystems. Chun Yuan-UNRELATED: Grants/Grants Pending: National Institutes of Health, American Heart Association, Philips Healthcare.* Andrew Buckler-UNRELATED: Employment: Elucid Bioimaging. Davide Capodanno-UNRELATED: Board Membership: Medtronic, Comments: speaker's fee; Consultancy: BIOTRONIK, Comments: speaker's fee; Employment: Boston Scientific, Comments: speaker's fee; Expert Testimony: Daiichi Sankyo, Comments: speaker's fee; Grants/Grants Pending: Boehringer Ingelheim, Comments: speaker's fee; Payment for Lectures Including Service on Speakers Bureaus: Bayer AG, Comments: speaker's fee; Payment for Manuscript Preparation: AstraZeneca, Comments: speaker's fee. Ulf Hedin—UNRELATED: Employment: Karolinska Hospital; Grants/Grants Pending: Swedish Research Council. Waleed Brinjikji-UNRELATED: Consultancy: MicroVention, Cerenovus*; Stock/Stock Options: Marblehead Medical LLC. Thomas Hatsukami-UNRELATED: Grants/Grants Pending: investigator-initiated grant from Philips Healthcare, completed December 31, 2018.* Christopher Hess—UNRELATED: Personal Fees: GE Healthcare, Focused Ultrasound Foundation, uniQure, Comments: consultant for GE Healthcare and Data and Safety Monitoring Board member for Focused Ultrasound Foundation and uniQure; Nonfinancial Support: Siemens, Comments: research travel. Bruce A. Wasserman-UNRELATED: Grants/Grants Pending: National Institutes of Health R01.* Joanna Wardlaw-RELATED: Grant: National Institute for Health Research Health Technology Assessment Panel, Comments: funded the research.* Ajay Gupta_UNRELATED: Consultancy: ERT; Travel/Accommodations/Meeting Expenses Unrelated to Activities Listed: Siemens, GE Healthcare. Jie Sun-UNRELATED: Grants/Grants Pending: American Heart Association, Institute of Translational Health Sciences.* Niranjan Balu—UNRELATED: Patents (Planned, Pending or Issued): I hold a US patent 9,557,396 but no payment/ royalties. *Money paid to the institution.

\section{REFERENCES}

1. GBD 2016 Stroke Collaborators. Global, regional, and national burden of stroke, 1990-2016: a systematic analysis for the Global Burden of Disease Study 2016. Lancet Neurol 2019;18:43-58 CrossRef Medline

2. Cheng SF, Brown MM, Simister RJ, et al. Contemporary prevalence of carotid stenosis in patients presenting with ischaemic stroke. $\mathrm{Br}$ J Surg 2019;106:872-78 CrossRef Medline

3. Mohr JP, Caplan LR, Melski JW, et al. The Harvard Cooperative Stroke Registry: a prospective registry. Neurology 1978;28:754-62 CrossRef Medline

4. Kumamaru H, Jalbert JJ, Nguyen LL, et al. Surgeon case volume and 30-day mortality after carotid endarterectomy among contemporary Medicare beneficiaries: before and after national coverage determination for carotid artery stenting. Stroke 2015;46:1288-94 CrossRef Medline

5. Abbott AL, Adelman MA, Alexandrov AV, et al. Why calls for more routine carotid stenting are currently inappropriate: an international, multispecialty, expert review and position statement. Stroke 2013;44:1186-90 CrossRef Medline

6. Munster AB, Franchini AJ, Qureshi MI, et al. Temporal trends in safety of carotid endarterectomy in asymptomatic patients. Neurology 2015;85:365-72 CrossRef Medline 
7. Ridker PM, Everett BM, Thuren T, et al. CANTOS Trial Group. Antiinflammatory therapy with canakinumab for atherosclerotic disease. N Engl J Med 2017;377:1119-31 CrossRef Medline

8. Abbott AL. Medical (nonsurgical) intervention alone is now best for prevention of stroke associated with asymptomatic severe carotid stenosis: results of a systematic review and analysis. Stroke 2009;40:e573-83 CrossRef Medline

9. Naylor AR, Gaines PA, Rothwell PM. Who benefits most from intervention for asymptomatic carotid stenosis: patients or professionals? Eur J Vasc Endovasc Surg 2009;37:625-32 CrossRef Medline

10. Naylor AR. Time to rethink management strategies in asymptomatic carotid artery disease. Nat Rev Cardiol 2011;9:116-24 CrossRef Medline

11. Ibrahimi P, Jashari F, Bajraktari G, et al. Ultrasound assessment of carotid plaque echogenicity response to statin therapy: a systematic review and meta-analysis. Int J Mol Sci 2015;16:10734-47 CrossRef Medline

12. Perisic L, Aldi S, Sun Y, et al. Gene expression signatures, pathways and networks in carotid atherosclerosis. J Intern Med 2016;279:293308 CrossRef Medline

13. Mujaj B, Bos D, Selwaness M, et al. Statin use is associated with carotid plaque composition: the Rotterdam Study. Int J Cardiol 2018;260:213-18 CrossRef Medline

14. Karlöf E, Seime T, Dias N, et al. Correlation of computed tomography with carotid plaque transcriptomes associates calcification with lesion-stabilization. Atherosclerosis 2019;288:175-85 CrossRef Medline

15. Kapadia M, Mehri-Basha M, Madhavan R, et al. High rate of inappropriate carotid endarterectomy in an urban medical center. $J$ Stroke Cerebrovasc Dis 2009;18:277-80 CrossRef Medline

16. Barnett HJ, Taylor DW, Eliasziw M, et al. Benefit of carotid endarterectomy in patients with symptomatic moderate or severe stenosis. N Engl J Med 1998;339:1415-25 CrossRef Medline

17. Endarterectomy for asymptomatic carotid artery stenosis: Executive Committee for the Asymptomatic Carotid Atherosclerosis Study. JAMA 1995;273:1421-28 Medline

18. Abbott AL, Paraskevas KI, Kakkos SK, et al. Systematic review of guidelines for the management of asymptomatic and symptomatic carotid stenosis. Stroke 2015;46:3288-301 CrossRef Medline

19. Ricotta JJ, Aburahma A, Ascher E, et al. Updated Society for Vascular Surgery guidelines for management of extracranial carotid disease. J Vasc Surg 2011;54:e1-31 CrossRef Medline

20. Ricotta JJ, AbuRahma A, Ascher E, et al. Updated Society for Vascular Surgery guidelines for management of extracranial carotid disease: executive summary. J Vasc Surg 2011;54:832-36 CrossRef Medline

21. Lanza G, Ricci S, Setacci C, et al. An update on Italian Stroke Organization guidelines on carotid endarterectomy and stenting. Int J Stroke 2014;9 Suppl A100:14-19 CrossRef Medline

22. Naylor AR, Ricco JB, de Borst GJ, et al. Editor's Choice: Management of Atherosclerotic Carotid and Vertebral Artery Disease-2017 Clinical Practice Guidelines of the European Society for Vascular Surgery (ESVS). Eur J Vasc Endovasc Surg 2018;55:3-81 CrossRef Medline

23. Aboyans V, Ricco JB, Bartelink ML, et al. ESC Scientific Document Group. 2017 ESC Guidelines on the Diagnosis and Treatment of Peripheral Arterial Diseases, in collaboration with the European Society for Vascular Surgery (ESVS): document covering atherosclerotic disease of extracranial carotid and vertebral, mesenteric, renal, upper and lower extremity arteries endorsed by: the European Stroke Organization (ESO), The Task Force for the Diagnosis and Treatment of Peripheral Arterial Diseases of the European Society of Cardiology (ESC), and of the European Society for Vascular Surgery (ESVS). Eur Heart J 2018;39:763-816 CrossRef Medline

24. Kopczak A, Schindler A, Bayer-Karpinska A, et al. Complicated carotid artery plaques as a cause of cryptogenic stroke. J Am Coll Cardiol 2020;76:2212-22 CrossRef Medline
25. Estol CJ. Dr C: Miller Fisher and the history of carotid artery disease. Stroke 1996;27:559-66 CrossRef Medline

26. Ogata J, Masuda J, Yutani C, et al. Rupture of atheromatous plaque as a cause of thrombotic occlusion of stenotic internal carotid artery. Stroke 1990;21:1740-45 CrossRef Medline

27. Carr S, Farb A, Pearce WH, et al. Atherosclerotic plaque rupture in symptomatic carotid artery stenosis. J Vasc Surg 1996;23:755-65 discussion 765-66 CrossRef Medline

28. Avril G, Batt M, Guidoin R, et al. Carotid endarterectomy plaques: correlations of clinical and anatomic findings. Ann Vasc Surg 1991;5:50-54 CrossRef Medline

29. Lusby RJ, Ferrell LD, Ehrenfeld WK, et al. Carotid plaque hemorrhage. Arch Surg 1982;117:1479-88 CrossRef Medline

30. Imparato AM, Riles TS, Mintzer R, et al. The importance of hemorrhage in the relationship between gross morphologic characteristics and cerebral symptoms in $\mathbf{3 7 6}$ carotid artery plaques. Ann Surg 1983;197:195-203 CrossRef Medline

31. Kwee RM. Systematic review on the association between calcification in carotid plaques and clinical ischemic symptoms. J Vasc Surg 2010;51:1015-25 CrossRef Medline

32. Finn AV, Nakano M, Narula J, et al. Concept of vulnerable/unstable plaque. Arterioscler Thromb Vasc Biol 2010;30:1282-92 CrossRef Medline

33. Gunning AJ, Pickering GW, Robb-Smith AH, et al. Mural thrombosis of the internal carotid artery and subsequent embolism. $Q J$ Med 1964;33:155-95 Medline

34. Eikelboom BC, Riles TR, Mintzer R, et al. Inaccuracy of angiography in the diagnosis of carotid ulceration. Stroke 1983;14:882-85 CrossRef Medline

35. Ammar $\mathrm{AD}$, Wilson $\mathrm{RL}$, Travers $\mathrm{H}$, et al. Intraplaque hemorrhage: its significance in cerebrovascular disease. Am J Surg 1984;148:84043 CrossRef Medline

36. Ricotta JJ, Schenk EA, Ekholm SE, et al. Angiographic and pathologic correlates in carotid artery disease. Surgery 1986;99:284-92

37. Lennihan L, Kupsky WJ, Mohr JP, et al. Lack of association between carotid plaque hematoma and ischemic cerebral symptoms. Stroke 1987;18:879-81 CrossRef Medline

38. Svindland A, Torvik A. Atherosclerotic carotid disease in asymptomatic individuals: An histological study of $\mathbf{5 3}$ cases. Acta Neuro Scand 1988;78:506-17 CrossRef Medline

39. Bassiouny HS, Davis H, Massawa N, et al. Critical carotid stenoses morphologic and chemical similarity between symptomatic and asymptomatic plaques. J Vasc Surg 1989;9:202-12 Medline

40. Bassiouny HS, Sakaguchi Y, Mikucki SA, et al. Juxtalumenal location of plaque necrosis and neoformation in symptomatic carotid stenosis. J Vasc Surg 1997;26:585-94 CrossRef Medline

41. Fisher CM, Ojemann RG. A clinico-pathologic study of carotid endarterectomy plaques. Rev Neurol (Paris) 1986;142:573-89 Medline

42. Loree HM, Kamm RD, Stringfellow RG, et al. Effects of fibrous cap thickness on peak circumferential stress in model atherosclerotic vessels. Circ Res 1992;71:850-58 CrossRef Medline

43. Stary HC, Chandler AB, Dinsmore RE, et al. A definition of advanced types of atherosclerotic lesions and a histological classification of atherosclerosis: a report from the Committee on Vascular Lesions of the Council on Arteriosclerosis, American Heart Association. Arterioscler Thromb Vasc Biol 1995;15:1512-31 CrossRef Medline

44. Stary HC. Natural history and histological classification of atherosclerotic lesions: an update. [Editorial]. Arterioscler Thromb Vasc Biol 2000;20:1177-78 CrossRef Medline

45. Cai JM, Hatsukami TS, Ferguson MS, et al. Classification of human carotid atherosclerotic lesions with in vivo multicontrast magnetic resonance imaging. Circulation 2002;106:1368-73

46. Hetterich $\mathrm{H}$, Webber $\mathrm{N}$, Willner M, et al. AHA classification of coronary and carotid atherosclerotic plaques by grating-based phasecontrast computed tomography. Eur Radiol 2016;26:3223-33 CrossRef Medline 
47. Virmani R, Kolodgie FD, Burke AP, et al. Lessons from sudden coronary death: a comprehensive morphological classification scheme for atherosclerotic lesions. Arterioscler Thromb Vasc Biol 2000;20:1262-75 CrossRef Medline

48. Virmani R, Burke AP, Farb A, et al. Pathology of the vulnerable plaque. J Am Coll Cardiol 2006;47:(8 Suppl):C13-18 CrossRef Medline

49. Qureshi AI, Janardhan V, Bennett SE, et al. Who should be screened for asymptomatic carotid artery stenosis? Experience from the Western New York Stroke Screening Program. J Neuroimaging 2001;11:105-11 CrossRef Medline

50. Yaghi S, Elkind MV. Cryptogenic stroke: a diagnostic challenge. Neurol Clin Pract 2014;4:386-93 CrossRef Medline

51. Yaghi S, Bernstein RA, Passman R, et al. Cryptogenic stroke: research and practice. Circ Res 2017;120:527-40 CrossRef Medline

52. Ferguson GG, Eliasziw M, Barr HW, et al. Surgical results in 1415 patients. Stroke 1999;30:1751-58 CrossRef Medline

53. Saam T, Hetterich H, Hoffmann V, et al. Meta-analysis and systematic review of the predictive value of carotid plaque hemorrhage on cerebrovascular events by magnetic resonance imaging. J Am Coll Cardiol 2013;62:1081-91 CrossRef Medline

54. Gupta A, Baradaran H, Schweitzer AD, et al. Carotid plaque MRI and stroke risk: a systematic review and meta-analysis. Stroke 2013;44:3071-77 CrossRef Medline

55. Schindler A, Schinner R, Altaf N, et al. Prediction of stroke risk by detection of hemorrhage in carotid plaques: meta-analysis of individual patient data. JACC Cardiovasc Imaging 2020;13(2 Pt 1):395406 CrossRef Medline

56. Nandalur KR, Hardie AD, Raghavan P, et al. Composition of the stable carotid plaque: Insights from a multidetector computed tomography study of plaque volume. Stroke 2007;38:935-40 CrossRef Medline

57. Saba L, Saam T, Jäger HR, et al. Imaging biomarkers of vulnerable carotid plaques for stroke risk prediction and their potential clinical implications. Lancet Neurol 2019;4422:1-14 CrossRef Medline

58. Simpson RJ, Akwei S, Hosseini AA, et al. MR imaging-detected carotid plaque hemorrhage is stable for 2 years and a marker for stenosis progression. Am J Neuroradiol 2015;36:1171-75 CrossRef Medline

59. Underhill HR, Yuan C. Carotid MRI: a tool for monitoring individual response to cardiovascular therapy? Expert Rev Cardiovasc Ther 2011;9:63-80 CrossRef Medline

60. Takaya N, Yuan C, Chu B, et al. Presence of intraplaque hemorrhage stimulates progression of carotid atherosclerotic plaques: a high-resolution magnetic resonance imaging study. Circulation 2005;111:2768-75 CrossRef Medline

61. Underhill HR, Yuan C, Yarnykh VL, et al. Arterial remodeling in [corrected] subclinical carotid artery disease. JACC Cardiovasc Imaging 2009;2:1381-89 CrossRef Medline

62. Underhill HR, Yuan C, Yarnykh VL, et al. Predictors of surface disruption with $\mathrm{MR}$ imaging in asymptomatic carotid artery stenosis. AJNR Am J Neuroradiol 2010;31:487-93 CrossRef Medline

63. Sun J, Underhill HR, Hippe DS, et al. Sustained acceleration in carotid atherosclerotic plaque progression with intraplaque hemorrhage: a long-term time course study. JACC Cardiovasc Imaging 2012;5:798-804 CrossRef Medline

64. Pletsch-Borba L, Selwaness M, van der Lugt A, et al. Change in carotid plaque components: a 4-year follow-up study with serial MR imaging. JACC Cardiovasc Imaging 2018;11:184-92 CrossRef Medline

65. Burke AP, Kolodgie FD, Farb A, et al. Healed plaque ruptures and sudden coronary death: evidence that subclinical rupture has a role in plaque progression. Circulation 2001;103:934-40 CrossRef Medline

66. Corti R, Fayad ZA, Fuster V, et al. Effects of lipid-lowering by simvastatin on human atherosclerotic lesions: a longitudinal study by highresolution, noninvasive magnetic resonance imaging. Circulation 2001;104:249-52 CrossRef Medline
67. Zhao X-Q, Dong L, Hatsukami T, et al. MR imaging of carotid plaque composition during lipid-lowering therapy a prospective assessment of effect and time course. JACC Cardiovasc Imaging 2011;4:977-86 CrossRef Medline

68. Underhill HR, Yuan C, Zhao XQ, et al. Effect of rosuvastatin therapy on carotid plaque morphology and composition in moderately hypercholesterolemic patients: a high-resolution magnetic resonance imaging trial. Am Heart J 2008;155:584.e1-8 CrossRef Medline

69. DeMarco JK, Spence JD. Plaque assessment in the management of patients with asymptomatic carotid stenosis. Neuroimaging Clin $\mathrm{N}$ Am 2016;26:111-27 CrossRef Medline

70. Spence JD, Hackam DG. Treating arteries instead of risk factors: a paradigm change in management of atherosclerosis. Stroke 2010;41:1193-99 CrossRef Medline

71. Spence JD, Coates V, Li H, et al. Effects of intensive medical therapy on microemboli and cardiovascular risk in asymptomatic carotid stenosis. Arch Neurol 2010;67:180-86 CrossRef Medline

72. GBD 2016 Neurology Collaborators. Global, regional, and nationa burden of neurological disorders, 1990-2016: a systematic analysis for the Global Burden of Disease Study 2016. Lancet Neurol 2019;18:459-80 CrossRef Medline

73. Iso H, Jacobs DR, Wentworth D, et al. Serum cholesterol levels and six-year mortality from stroke in $\mathbf{3 5 0 , 9 7 7}$ men screened for the multiple risk factor intervention trial. N Engl J Med 1989;320:90410 CrossRef Medline

74. Chan DK, O'Rourke F, Shen Q, et al. Meta-analysis of the cardiovascular benefits of intensive lipid lowering with statins. Acta Neurol Scand 2011;124:188-95 CrossRef Medline

75. Cannon CP, Steinberg BA, Murphy SA, et al. Meta-analysis of cardiovascular outcomes trials comparing intensive versus moderate statin therapy. J Am Coll Cardiol 2006;48:438-45 CrossRef Medline

76. Everett BM, Glynn RJ, MacFadyen JG, et al. Rosuvastatin in the prevention of stroke among men and women with elevated levels of $C$ reactive protein: Justification for the Use of Statins in Prevention: an Intervention Trial Evaluating Rosuvastatin (JUPITER). Circulation 2010;121:143-50 CrossRef Medline

77. Cannon CP, Blazing MA, Giugliano RP, et al. Ezetimibe added to statin therapy after acute coronary syndromes. $N$ Engl $\mathrm{J} \mathrm{Med}$ 2015;372:2387-97 CrossRef Medline

78. Sabatine MS, Giugliano RP, Keech AC, et al. Evolocumab and clinical outcomes in patients with cardiovascular disease. $N$ Engl J Med 2017;376:1713-22 CrossRef Medline

79. Landmesser U, Chapman MJ, Stock JK, et al. 2017 Update of ESC/ EAS Task Force on practical clinical guidance for proprotein convertase subtilisin/kexin type 9 inhibition in patients with atherosclerotic cardiovascular disease or in familial hypercholesterolaemia. Eur Heart J 2018;39:1131-43 CrossRef Medline

80. O'Brien KD, Hippe DS, Chen $\mathrm{H}$, et al. Longer duration of statin therapy is associated with decreased carotid plaque vascularity by magnetic resonance imaging. Atherosclerosis 2016;245:74-81 CrossRef

81. Du R, Cai J, Cui B, et al. Rapid improvement in carotid adventitial angiogenesis and plaque neovascularization after rosuvastatin therapy in statin treatment-naïve subjects. J Clin Lipidol 2019;13:847-53 CrossRef Medline

82. The International Stroke Trial (IST): a randomised trial of aspirin, subcutaneous heparin, both, or neither among 19435 patients with acute ischaemic stroke-International Stroke Trial Collaborative Group. Lancet (London, England) 1997;349:1569-81 CrossRef Medline

83. Russell DA, Wijeyaratne SM, Gough MJ. Relationship of carotid plaque echomorphology to presenting symptom. Eur J Vasc Endovasc Surg 2010;39:134-38 CrossRef Medline

84. Halkes PH, van Gijn J, Kappelle LJ, et al. ESPRIT Study Group. Aspirin plus dipyridamole versus aspirin alone after cerebral ischaemia of arterial origin (ESPRIT): randomised controlled trial. Lancet 2006;367:1665-73 CrossRef Medline

85. Diener HC, Sacco RL, Yusuf S, et al. Prevention Regimen for Effectively Avoiding Second Strokes (PRoFESS) study group. Effects 
of aspirin plus extended-release dipyridamole versus clopidogrel and telmisartan on disability and cognitive function after recurrent stroke in patients with ischaemic stroke in the Prevention Regimen for Effectively Avoiding Second Strokes (PRoFESS) trial: a double-blind, active and placebo-controlled study. Lancet Neurol 2008;7:875-84 CrossRef Medline

86. Madani A, Beletsky V, Tamayo A, et al. High-risk asymptomatic carotid stenosis: ulceration on 3D ultrasound vs TCD microemboli. Neurology 2011;77:744-50 CrossRef Medline

87. Kakkos SK, Griffin MB, Nicolaides AN, et al. The size of juxtaluminal hypoechoic area in ultrasound images of asymptomatic carotid plaques predicts the occurrence of stroke. J Vasc Surg 2013;57:60918.e1; discussion 617-18 CrossRef Medline

88. Rothwell PM, Algra A, Chen Z, et al. Effects of aspirin on risk and severity of early recurrent stroke after transient ischaemic attack and ischaemic stroke: time-course analysis of randomised trials. Lancet 2016;388:365-75 CrossRef Medline

89. Bhatt DL, Fox KA, Hacke W, et al. CHARISMA Investigators. Clopidogrel and aspirin versus aspirin alone for the prevention of atherothrombotic events. $N$ Engl J Med 2006;354:1706-17 CrossRef Medline

90. Hong S, Nam M, Little BB, et al. Randomized control trial comparing the effect of cilostazol and aspirin on changes in carotid intima-medial thickness. Heart Vessels 2019;34:1758-68 CrossRef Medline

91. Eikelboom JW, Connolly SJ, Bosch J, et al. Rivaroxaban with or without aspirin in stable cardiovascular disease. $N$ Engl J Med 2017;377:1319-30 CrossRef Medline
92. Ameriso SF, Amarenco P, Pearce LA, et al. Intracranial and systemic atherosclerosis in the NAVIGATE ESUS trial: recurrent stroke risk and response to antithrombotic therapy. J Stroke Cerebrovasc Dis 2020;29:104936 CrossRef Medline

93. Seneviratne AN, Monaco C. Role of inflammatory cells and toll-like receptors in atherosclerosis. Curr Vasc Pharmacol 2015;13:146-60 CrossRef Medline

94. Bäck M, Hansson GK. Anti-inflammatory therapies for atherosclerosis. Nat Rev Cardiol 2015;12:199-211 CrossRef Medline

95. Tsivgoulis G, Katsanos AH, Giannopoulos G, et al. The role of colchicine in the prevention of cerebrovascular ischemia. Curr Pharm Des 2018;24:668-74 CrossRef Medline

96. Nidorf SM, Eikelboom JW, Budgeon CA, et al. Low-dose colchicine for secondary prevention of cardiovascular disease. J Am Coll Cardiol 2013;61:404-10 CrossRef Medline

97. Choi H, Uceda DE, Dey AK, et al. Treatment of psoriasis with biologic therapy is associated with improvement of coronary artery plaque lipid-rich necrotic core: results from a prospective, observational study. Circ Cardiovasc Imaging 2020;13:e011199 CrossRef Medline

98. Mahmoud R, Moody AR, Foster M, et al. Sharing de-identified medical images electronically for research: a survey of patients' opinion regarding data management. Can Assoc Radiology J 2019;70:212-18 CrossRef Medline

99. Paraskevas KI, Eckstein HH, Mikhailidis DP, et al. Rationale for screening selected patients for asymptomatic carotid artery stenosis. Curr Med Res Opin 2020;36:361-65 CrossRef Medline 